\title{
Gestión curricular en centros educativos costarricenses: Un análisis desde la percepción docente y la dirección
}

\section{Curriculum Management in Costa Rican Schools: An Analysis from Teaching Staff and Administration Team's Perception \\ Organização curricular nos centros educativos da Costa Rica: uma análise a partir da percepção dos professores e da administração}

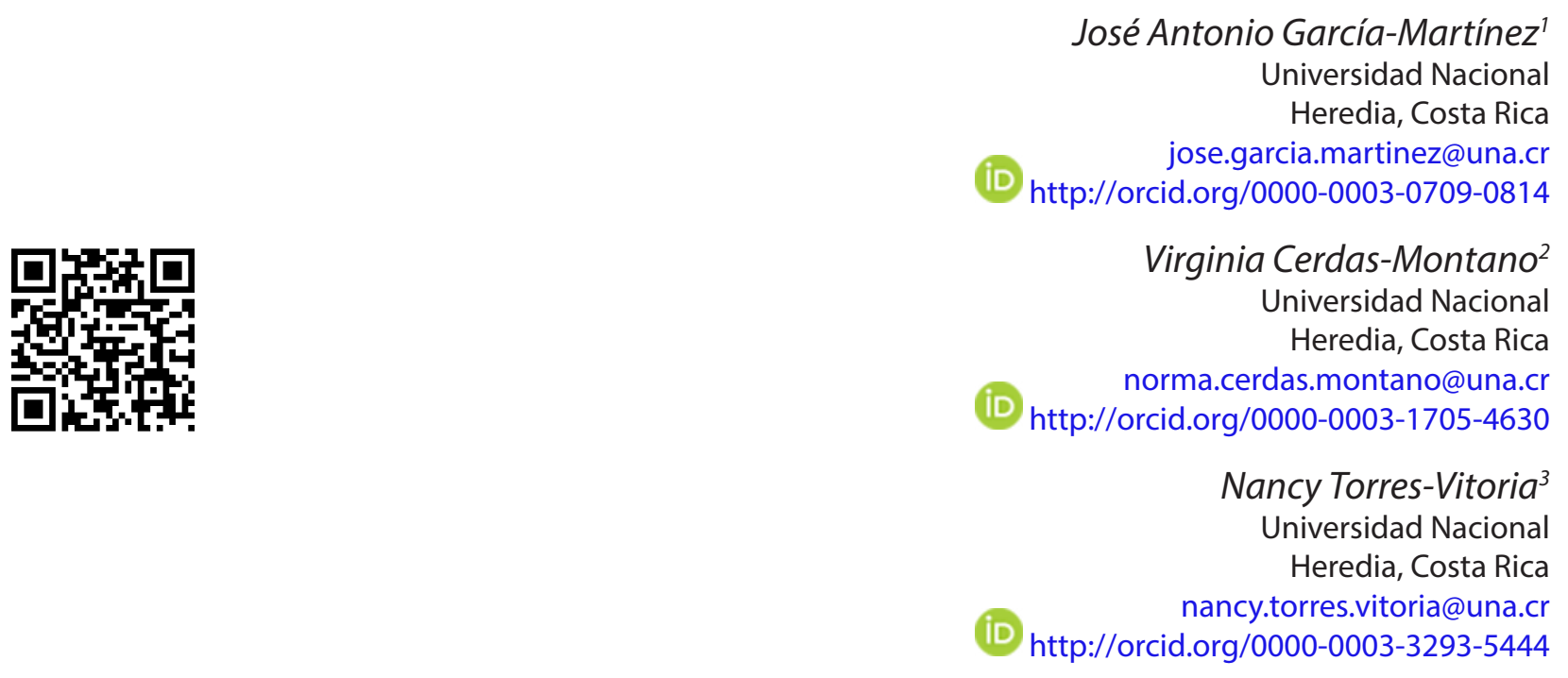

Recibido • Received • Recebido: 05 / 10 / 2016

Corregido • Revised • Revisado: 19 / 10 / 2017

Aceptado•Accepted • Aprovado: 23/ $11 / 2017$

\footnotetext{
${ }^{1}$ Máster en Educación y Tecnologías con énfasis en Investigación por la Universidad Obierta de Catalunya. Ejerce como docente e investigador en la División de Educación para el Trabajo (CIDE) de la Universidad Nacional, Costa Rica.

${ }^{2}$ Doctora en Educación con especialidad en Mediación Pedagógica. Especialidad en Gestión Educativa con énfasis en Liderazgo, ejerce como académica e investigadora en la División de Educación para el Trabajo (CIDE) de la Universidad Nacional, Costa Rica.

${ }^{3}$ Doctora en Educación con especialidad en Mediación Pedagógica. Historiadora y curriculista, ejerce como académica e investigadora en la División de Educación Rural y la División de Educación para el Trabajo (CIDE) de la Universidad Nacional, Costa Rica.
} 
doi: http://dx.doi.org/10.15359/ree.22-1.11

URL: http://www.una.ac.cr/educare

CORREO: educare@una.cr

Resumen: La gestión curricular es uno de los procesos dinamizadores más importantes en un centro escolar, ya que concretiza las políticas educativas vigentes de una nación. El sistema educativo costarricense no es la excepción, y si bien la gestión curricular es responsabilidad de la dirección, es el colectivo docente desde las aulas el que la acciona. El presente estudio tiene el objetivo de analizar aspectos relacionados con la gestión curricular desde la perspectiva docente y de la dirección. La metodología se basa en un enfoque mixto, desde una dimensión cuantitativa a través de un diseño ex post facto y transversal, mientras la cualitativa con un método fenomenológico. La recolección de datos se realiza con un cuestionario ad hoc aplicado a 192 docentes y entrevistas semiestructuradas a seis responsables de la dirección de centros educativos públicos. Los resultados muestran, tanto desde la percepción docente como de la dirección, una clara vinculación entre la gestión curricular y los procesos áulicos, igualmente las principales redes de apoyo con que cuentan los centros educativos están relacionadas con los comités de adecuaciones curriculares, donde queda excluido el Patronato Escolar y las Juntas de Educación. Por otro lado, el colectivo docente relaciona el fracaso escolar con la falta de apoyo familiar y, por el contrario, vincula la promoción estudiantil con el esfuerzo docente.

Palabras claves: Gestión curricular; políticas curriculares; promoción estudiantil; fracaso escolar; gestión educativa.

Abstract: Curriculum management is one of the main energizing processes in a school because it brings to reality the education policies that are being enforced in a nation. The Costa Rican education system is no exception, and although the head of every school is responsible for curriculum management, it is in the classroom, and by the teaching staff, that it is truly enforced. This study aims to analyze those aspects related to curriculum management from both the teachers and the head of the school's perspective. The methodology is based on a mixed approach: the quantitative dimension through a transversal and ex post facto design, and qualitative dimension through a phenomenological method. Data collection was made by an ad hoc questionnaire applied to 192 teachers, and semi-structured interviews applied to six heads of public schools. The results show that, for the teaching staff and the heads of the schools, there is a clear bond between curricular management and in-classroom processes. In the same way, the main support networks that the schools have are linked to the Curricular Adaptations Committees, and this excludes the School Board and the Board of Education. On the other side, the teaching staff relates school failure with the lack of support from the student's family, and on the contrary, the staff links student success and promotion with teaching effort.

Keywords: Curricular management; curricular policies; student promotion; school failure: education management.

Resumo: A organização curricular é um dos processos dinâmicos mais importantes em um centro educativo, porque concretiza as políticas educacionais atuais de uma nação. O sistema educativo costarriquenho não é exceção e, embora a organização do currículo é de responsabilidade da administração, é um trabalho feito pela equipe docente desde as salas de aula. O objetivo deste estudo é analisar os aspectos relacionados com a organização do currículo, a partir da perspectiva do professor e da administração do centro educativo. A metodologia é baseada em uma abordagem mista, a partir de uma dimensão quantitativa através de um projeto transversal e qualitativa, utilizando o método fenomenológico. A coleta de dados é realizada por meio de um questionário ad hoc aplicado 
a 192 professores, e entrevistas semiestruturadas a seis pessoas responsáveis pela administração dos centros educativos públicos. Os resultados mostram que na da percepção do docente como da administração, existe uma relação evidente entre a organização curricular e os processos dentro das aulas, também as principais redes de apoio escolar disponíveis estão relacionadas com os comitês de adequações curriculares, aonde são excluídos o Conselho Escolar e o Conselho de Educação. Por outro lado, a equipe docente relaciona o fracasso escolar com a falta de apoio da família e também relaciona a promulgação do sucesso escolar com o esforço da equipe docente.

Palavras-chave: Organização curricular; políticas curriculares; promoção do aluno; fracasso escolar; gestão educacional.

\section{Introducción}

Este estudio pertenece al proyecto de investigación denominado"Tendencias y desafíos de la administración costarricense", donde se plantean objetivos en relación con dos dimensiones de investigación, la administrativa y la curricular. El presente escrito se centra en la dimensión curricular.

El hecho educativo se caracteriza por dinámicas complejas y cambiantes que se abordan desde una mirada multidimensional (Vázquez, 2013) ya que, desde un solo foco de atención, reduce las posibilidades de una comprensión integral de la gestión curricular.

Desde esta posición multidimensional, se asume un currículo prescrito (Ortiz, 2013) por el sistema educativo que se encuentra en toda la estructura organizativa, que comprende desde los programas, los proyectos, hasta protocolos que se accionan para normar el comportamiento del estudiantado. Por otro lado, se encuentra un currículo oculto, que se acciona desde las prácticas cotidianas y que conlleva una dimensión emocional, asociado con experiencias de vida de los sujetos participantes, sus valores, su cultura y que, en ocasiones, se antepone al currículo formalmente prescrito en las instituciones (Da Silva, 2013). Por ello, se considera relevante conocer las percepciones de los agentes intervinientes en el hecho educativo, ya que son las personas que concretizan la integralidad de la dimensión curricular que se desarrolla en los centros educativos.

La comprensión de la realidad desde las personas que accionan los contextos educativos es un punto medular en este análisis, por ello se realiza desde una perspectiva que recoge tanto la percepción de la dirección de los centros educativos, como la del personal docente, lo que permitirá establecer elementos relevantes de análisis y contribuir a procesos de discusión con miras al mejoramiento de las prácticas educativas.

Del mismo modo, se introducen algunas ideas teóricas sobre la dimensión curricular: a) los componentes o elementos que intervienen, b) las políticas curriculares, c) procesos áulicos en relación con redes de apoyo, d) algunos indicadores de logro. 
El objetivo de este estudio es analizar, desde la percepción del colectivo docente y de la dirección, aspectos relacionados con la gestión curricular de los centros educativos y, específicamente, se pretende:

1. Identificar los aspectos de mayor relevancia que intervienen en la gestión curricular.

2. Determinar el conocimiento respecto a la procedencia de las políticas curriculares que se implementan en los centros educativos.

3. Describir las principales redes de apoyo con que cuentan los centros educativos.

4. Identificar los aspectos más relevantes que se vinculan con la promoción estudiantil y fracaso escolar.

\section{Antecedentes}

La naturaleza de la gestión de centros educativos es compleja y dinámica, está inmersa en contextos particulares que hace de cada uno de ellos un universo de posibilidades desde los cuales se pueden tener acercamientos e interpretaciones a esas realidades. Desde esta premisa de complejidad y dinamismo, en la cual se movilizan los centros educativos, se pretenden abordar diferentes componentes para el establecimiento de una dimensión integral de la gestión curricular.

Existen abordajes a la temática curricular desde diferentes ángulos de análisis. Ortiz (2013) desarrolla una investigación en la cual presenta hallazgos en relación con las distancias que se generan entre los programas y las herramientas que se diseñan para su utilización, como apoyo didáctico en los salones de clases y las dificultades de apropiación del colectivo docente.

Soler y Martínez (2014) muestran la necesidad de que el colectivo docente propicie espacios de análisis de actualización de las temáticas disciplinares, y desde su rol, ya que la gestión del currículo es la base del proceso de enseñanza aprendizaje. Concluye que la participación del personal docente para el desarrollo de políticas curriculares es sustantiva para la gestión del currículo en los diferentes espacios donde está inmerso, ya que el repensar de su propio quehacer es necesario como potenciador de calidad en procesos académicos.

Desde otra perspectiva, Brenes (2015) analiza el desarrollo de innovaciones pedagógicas desde la gestión administrativa, concluyendo la existencia de áreas susceptibles de mejora desde su implementación, su ejecución y su seguimiento.

Se puede reconocer, en los abordajes de la gestión curricular, una serie de áreas o dimensiones sujetas a análisis. En esta investigación se profundizará en algunos aspectos tales como la compresión de la gestión curricular, políticas curriculares, redes de apoyo y algunos indicadores de logro destacados por personal docente y la dirección de los centros educativos. 


\section{Marco teórico}

Para fines de esta investigación, se centra el punto de partida desde algunos referentes conceptuales que Chen y Vargas (2007) describen en cuatro grandes áreas básicas para la administración de los recursos institucionales. Entre las que se encuentran la infraestructura, el talento humano, el presupuesto y el área curricular.

Estas áreas se constituyen, a su vez, por diferentes elementos, por ejemplo, la infraestructura comprende los equipamientos tecnológicos, edificios, zonas verdes, materiales didácticos del centro educativo en relación con el proceso enseñanza-aprendizaje. El talento humano comprende la forma en cómo se gestiona el personal docente y administrativo en función del proceso de enseñanza-aprendizaje. Rico (2016), a su vez, contempla aspectos como la capacitación del personal de la organización en áreas cognitivas, metodológicas y didácticas. El área presupuestaria se vincula al manejo del dinero asignado por el Estado (ordinario) para la ejecución de planes y programas en cada centro educativo. Además, del manejo de fondos extraordinarios que son gestionados por los organismos de apoyo para solventar otros gastos que no son solventados por el presupuesto ordinario.

Por último, el área curricular cumple su papel de eje dinamizador de todo el quehacer del centro educativo. Es aquí donde se intersectan las otras áreas, para tomar un norte en función del proceso de enseñanza-aprendizaje, que se constituye en la brújula que direcciona cualquier acción de la gestión del centro y que se ajusta a la legislación del país de manera programada para el cumplimiento de los objetivos del sistema educativo (Segura, 2012).

De acuerdo con Castro (2005), el término gestión curricular comprende la construcción de saberes desde la dimensión teórica y práctica. En dicha construcción interactúan los actores sociales que participan de los procesos educativos (Díaz-Barriga, Luna y Jiménez-Vásquez, 2015). Uno de los aspectos que intervienen de forma directa es la gestión administrativa de la organización, en esta dinámica se complementan dimensiones pedagógicas y didácticas, que se constituyen en uno de los puntos medulares, desde donde se partirá para generar procesos de análisis y de mejoras.

El centro educativo dinamiza su gestión en torno a los procesos de enseñanza-aprendizaje, lo que es, sin lugar a dudas, una responsabilidad inmediata a cargo de docentes y dirección en las organizaciones educativas, de acuerdo con Castro (2005) al indicar que "la gestión del currículum se vincula directamente con los procesos de toma de decisiones en relación a qué, cómo y cuándo enseñar y evaluar, pues constituyen actividades centrales que se desarrollan en el establecimiento escolar" (p. 14).

Para este estudio, se tiene presente que existen planes y programas preestablecidos por el Ministerio de Educación Pública (MEP), los cuales son de ejecución obligatoria para todos los centros educativos del país. Sin embargo, cada centro está inmerso en su propio contexto que se 
doi: http://dx.doi.org/10.15359/ree.22-1.11

URL: http://www.una.ac.cr/educare

CORREO: educare@una.cr

constituye por su propia cultura organizacional, de acuerdo con Poggi (1998, citada por Castro, 2005), al indicar que existen dos vertientes para asumir el currículo “... primero el currículum considera las circunstancias sociales e históricas que atraviesan la enseñanza institucionalizada y segundo el currículum también aparece atravesado, determinado en parte, contextualizado por la cultura institucional escolar propia de cada establecimiento" (p. 14).

En esta reconstrucción del currículo propio de cada centro educativo, se hace imperante la comprensión del contexto desde el cual se acciona. Toma relevancia el análisis de las prácticas cotidianas que se establecen en los centros educativos, la cultura organizacional, las percepciones de sus actores sociales, los valores que se establecen en sus vínculos relacionales, el trabajo en equipo que se desarrolla, las políticas educativas a las que se debe responder, la relación con la comunidad, entre otros aspectos.

Entender las cosmovisiones que tienen los actores sociales que accionan los diversos contextos amplía el espectro de comprensión desde la gestión curricular, sin excluir la gestión administrativa, que está implícita en todo el accionar del centro, y que, según la IIPE-UNESCO (2004, citando a Antúnez, 1993), "es el conjunto de acciones que se realizan a fin de movilizar recursos (personas, tiempo, dinero, materiales, etc.) para la consecución de los objetivos de la institución" (p. 7).

Este proceso involucra planificación, establecimiento de responsabilidades, indicadores de logro claros, coordinación, evaluación y seguimiento, sin dejar de lado, el ajuste de los procesos que se accionan en relación con las políticas públicas que brindan un marco en donde se movilizan los centros educativos. Dichas políticas establecen planes y programas que se deben ejecutar de manera metódica en el sistema educativo y que responden a objetivos más amplios como el perfil de ciudadanía que se pretende desarrollar, como señala Rodríguez y Valencia citados por la IIPE-UNESCO (2004), "es casi imposible pensar en una organización compleja sin división de tareas y funciones, sin asignación de roles, sin normas y reglas sobre las qué basar su accionar" (p. 7).

En este sentido, la gestión administrativa continúa ligada estrechamente con la gestión curricular, ya que la primera debe ir en función de la segunda. Todas las acciones que se desarrollan en el centro educativo tendrían que priorizar el área curricular como eje dinamizador, es así como la preparación del cuerpo docente debería establecerse teniendo en cuenta las necesidades curriculares determinadas para el centro educativo de acuerdo con la especificidad de su contexto.

\section{La compresión de la gestión curricular}

En los diferentes abordajes que se hacen para la gestión curricular, los procesos de mediación pedagógica, los programas que se desarrollan en el salón de clases y las evaluaciones, son algunos de los aspectos que mayor familiaridad representan para la población docente,

\section{6} José Antonio García-Martínez, Virginia Cerdas-Montano y Nancy Torres-Vitoria

Los artículos de la Revista Electrónica Educare del Centro de Investigación y Docencia en Educación de la Universidad Nacional, Costa Rica, se comparten bajo términos de la Licencia Creative Commons: Reconocimiento, № Comercial, Sin Obra Derivada 3.0 Costa Rica. Las autorizaciones adicionales a las aquí delimitadas se pueden obtener en el correo: educare@una.cr 
sin embargo, estudios como los de Díaz-Barriga e Inclán-Espinosa (2001) refieren la necesidad de ampliar la cosmovisión del colectivo docente desde una perspectiva integral del proceso trascendiendo el espacio del aula.

Partiendo de la premisa de que la gestión curricular debe integrar todos los elementos que intervienen en el proceso educativo, los servicios que complementan o favorecen el proceso de enseñanza-aprendizaje se deberían asumir como parte de esta misma, tales como como el transporte, comedor y lo relacionado con los servicios que el centro educativo ofrece a la población estudiantil. Sin embargo, los procesos pedagógicos propiamente dichos son los que se ligan principalmente con la gestión curricular y elementos circundantes en relación con la práctica docente.

Al respecto, la UNESCO (2011) refiere que los procesos pedagógicos, como la acción sustantiva de las organizaciones educativas, quedan ligados a sus miembros. En este sentido, el proceso de enseñanza-aprendizaje cobra relevancia y, por ende, el proyecto curricular, los planes y programas, así como los recursos y materiales que facilitan su concreción. Según Inciarte, Marcano y Reyes (2006), el cuerpo docente circunscribe sus prácticas a los espacios áulicos, y desde ahí acciona el currículo escolar, por lo cual queda patente la comprensión de la gestión curricular con la multidimensionalidad que la constituye.

\section{Políticas curriculares}

Las políticas educativas, tanto en la búsqueda del fortalecimiento y la armonización de procesos sociales educativos, así como en la construcción de consensos alrededor de los marcos conceptuales que se definen en los convenios nacionales e internacionales, buscan establecer acciones específicas que favorezcan la calidad de la educación en el sistema educativo. La Coordinación Educativa y Cultural Centroamericana (CECC/SICA, 2013) define las políticas educativas como "un conjunto de orientaciones para dotar a la región centroamericana en un marco general de acción en materia educativa, de acuerdo a [sic] las prioridades regionales identificadas" (p. 2).

En Costa Rica, al igual que en los demás países de la región, los acuerdos que se establecen por las autoridades ministeriales, en materia de educación, se concretizan en los centros educativos. La relevancia de este tema tiene relación con la percepción de las personas que implementan dichas políticas y su conocimiento con las entidades que las emanan como el MEP, Organización de las Naciones Unidas para la Educación (UNESCO), Fondo de las Naciones Unidas para la Infancia (UNICEF), Organización de Estados Iberoamericanos para la Educación, Ciencia y la Cultura (OEI), Banco Mundial (BM), universidades públicas y convenios internacionales.

En este sentido, las políticas y convenios emanados por estas organizaciones marcan el rumbo del país en materia educativa $y$, en los centros educativos donde se concretizan se requiere una visión integral del quehacer del colectivo docente, para cumplir de manera 
doi: http://dx.doi.org/10.15359/ree.22-1.11

URL: http://www.una.ac.cr/educare

CORREO: educare@una.cr

eficiente la tarea (Cerdas-Montano, Torres-Vitoria y García-Martínez, 2016); un trabajo en el cual no se tiene la visión global de lo que se está desarrollando puede tomar diversos rumbos, y no todos necesariamente llevan a la meta que se tiene prevista.

\section{Redes de apoyo}

La labor que se realiza en los centros educativos se conjuga con la preparación profesional del colectivo docente, su disposición, vocación y redes de apoyo desde los vínculos relacionales que puedan establecerse de manera formal e informal.

Desde esta perspectiva y de acuerdo con Bernasconi (2009, citando a Albornoz, 2009), las redes de apoyo se entienden como "formas de interacción social, espacios de convivencia y conectividad" (p. 8). Estas redes vendrían a conformar sistemas abiertos de interdependencias, donde las personas que participan de los procesos contribuyen a la búsqueda de soluciones para contextos específicos, en lugares y tiempos determinados para potenciar los recursos de los centros educativos.

Para desarrollar sistemas abiertos y potenciar los recursos se requiere un trabajo colaborativo de miembros del centro educativo (Molano, 2016; Rodríguez-Gómez y GairínSallán, 2015). Un trabajo individualizado puede dar resultados positivos; sin embargo, el trabajo colaborativo es un proceso sostenible a largo plazo y puede favorecer el logro de metas comunes con mayor eficiencia. Labores como las adecuaciones curriculares que se solicitan en todos los centros educativos conllevan procesos de dominio cognitivo y técnico, lo que requiere un esfuerzo por parte del colectivo docente, por lo que se hace necesario el establecimiento de las redes de apoyo. Muchas de las prácticas cotidianas que los cuerpos docentes deben desarrollar en los salones de clase responden a la gestión curricular, que se establece como obligatoria desde el sistema administrativo central.

Es importante destacar que la participación de las personas en las redes de apoyo requiere de habilidades sociales, culturales y de gestión, ya que los padres y madres de familia que participan en ellas, especialmente en organizaciones comunales como la Juntas de Educación y el Patronato Escolar, transitan por la experiencia de tomar decisiones, manejo de grupo, distribución de recursos, administración de fondos públicos y organización de eventos comunitarios, entre otros.

\section{Indicadores de logro}

Para Gómez-Sevilla y Sánchez-Mendoza (2013) los indicadores de logro permiten comprender la gestión curricular desde la verificación y evaluación de su accionar en relación con las metas propuestas. El Quinto informe estado de la educación (Programa Estado de la Nación, 2015), en el abordaje de los indicadores de logro en los centros educativos, denota

\section{8} José Antonio García-Martínez, Virginia Cerdas-Montano y Nancy Torres-Vitoria

Los artículos de la Revista Electrónica Educare del Centro de Investigación y Docencia en Educación de la Universidad Nacional, Costa Rica, se comparten bajo términos de la Licencia Creative Commons: Reconocimiento, № Comercial, Sin Obra Derivada 3.0 Costa Rica. Las autorizaciones adicionales a las aquí delimitadas se pueden obtener en el correo: educare@una.cr 
la existencia tanto de factores endógenos como exógenos de la evaluación de los procesos educativos. En cuanto al accionar del centro educativo, la responsabilidad directa recae en los aspectos endógenos tales como acceso a tecnologías de la información y la comunicación (TIC), personal docente, gestión del centro, entre otros. Sin embargo, algunos componentes exógenos son relevantes para el análisis de los indicadores de logro, tal como el contexto comunitario, el apoyo familiar, capacidades propias del estudiantado, sexo, edad, entre otros.

La conceptualización de los procesos de evaluación es variada; no obstante, en los salones de clases predominan prácticas tradicionales, en donde la evaluación responde principalmente a la dimensión sumativa, que potencia la acreditación de los conocimientos sobre la dimensión formativa, la cual busca una formación integral y funcional de todo el proceso tanto en el ámbito de aula como fuera de ella. Vallejo y Molina (2014) hacen una crítica ante esta evaluación tradicional instaurada en las prácticas educativas y proponen una evaluación auténtica, refiriéndose a dar sentido, significado y funcionalidad al proceso evaluativo. La memorización y repetición de contenidos son algunas de las prácticas tradicionales (Moreira, 2016) más comunes en los centros educativos, lo cual contrasta con indicadores de logro como la promoción, permanencia y retención estudiantil.

Dichos indicadores son accionados desde los salones de clases por el colectivo docente y desde las prácticas de gestión de la dirección de los centros educativos, cobrando gran relevancia como factores de éxito para las instituciones educativas, desde la evaluación externa del sistema educativo vigente.

\section{Metodología}

El trabajo que se presenta responde a una investigación de mayor envergadura, que recoge tanto el componente de gestión administrativa como curricular, aunque en este artículo se centrará solamente en el segundo.

La metodología utilizada (Figura 1), de acuerdo con los objetivos planteados, se aborda desde un enfoque mixto (Tashakkori y Teddlie, 2009), ya que evita la posible aparición de sesgos en los resultados al utilizar los distintos enfoques de forma aislada, además de que la complementariedad de los métodos ayuda al desarrollo del proceso (Rodríguez y Valldeoriola, 2009).

Concretamente, la metodología tendrá una aproximación concurrente, caracterizada por el abordaje desde los diferentes enfoques y la convergencia en la comparación de resultados (Creswell, 2009). En una primera instancia, el método cobra un carácter empírico-analítico, que sigue un proceso deductivo y con un diseño ex post facto, es decir, sin que exista una manipulación de las variables (Hernández, Fernández y Baptista, 2010). Desde este enfoque cuantitativo, la recolección de datos se realizó de manera transeccional o transversal (Hernández et al., 2010) con el colectivo docente. 
doi: http://dx.doi.org/10.15359/ree.22-1.11

URL: http://www.una.ac.cr/educare

CORREO: educare@una.cr

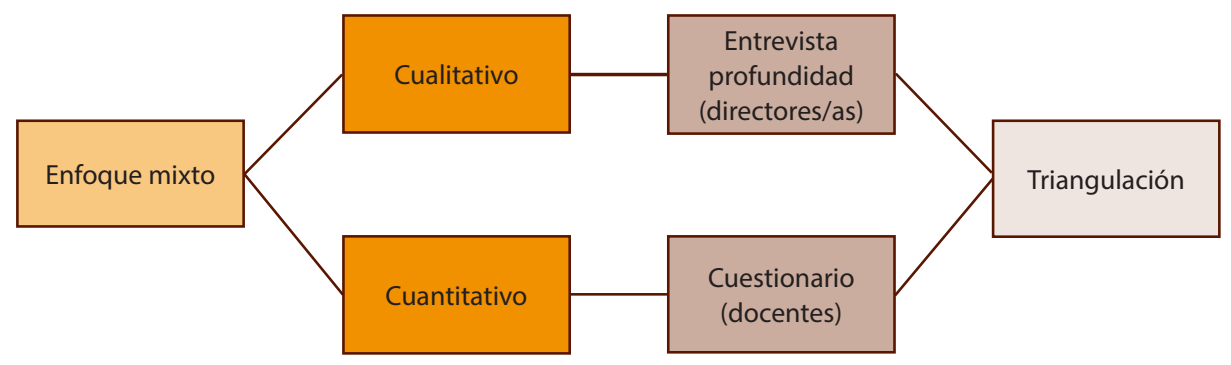

Figura 1: Enfoque y técnicas de recogida de datos (Cerdas-Montano et al., 2016, p. 124).

Por otro lado, y de manera paralela, desde un enfoque cualitativo y un método fenomenológico (Sabariego, Massot y Dorio, 2014) se busca entender el significado que el colectivo director da a aspectos relacionados con la gestión curricular.

\section{Selección de la muestra y participantes}

Se recogieron 246 cuestionarios de forma incidental en diez centros educativos de la Gran Área Metropolitana (Costa Rica), respondiendo a dos criterios: a) de los diferentes niveles del sistema público costarricense: preescolar, primaria y secundaria; b) de diferentes ámbitos: rural y urbano. Cabe destacar que dos de los centros se ubican en zonas de atención prioritaria.

Aspectos como la representatividad quedan de manifiesto en la Tabla 1, donde se observa la cantidad de los centros educativos públicos del país en comparación con la muestra obtenida y donde se aprecia la similitud de los porcentajes tanto poblacionales como muestrales en cada ámbito.

Tabla 1: Población y muestra según cantidad de centros educativos en los diferentes ámbitos

\begin{tabular}{lcccc}
\hline & \multicolumn{2}{c}{ Población* $^{*}$ Muestra } \\
\hline Ámbito & Frecuencia & Porcentaje & Frecuencia & Porcentaje \\
\hline Preescolar & 87 & 1,9 & 1 & 10,0 \\
Primaria & 3733 & 83,6 & 7 & 70,0 \\
Secundaria & 645 & 14,4 & 2 & 20,0 \\
\hline Total & 4465 & 100,0 & 10 & 100,0 \\
\hline
\end{tabular}

Fuente: Creación propia con indicadores del Departamento de Análisis Estadístico, MEP (2017).

* Los datos de la población corresponden al año 2015. 
Para facilitar el análisis de los resultados de este trabajo, se fijaron tres restricciones muestrales con posterioridad a la recogida de datos: a) tener al menos 1 año de laborar en el centro educativo en el momento de la recogida de datos; $b$ ) tener al menos dos años laborados como experiencia docente $y, c$ c cumplimentar al menos el $75 \%$ del instrumento. Después de la aplicación de estos criterios, la muestra final se situó en 192.

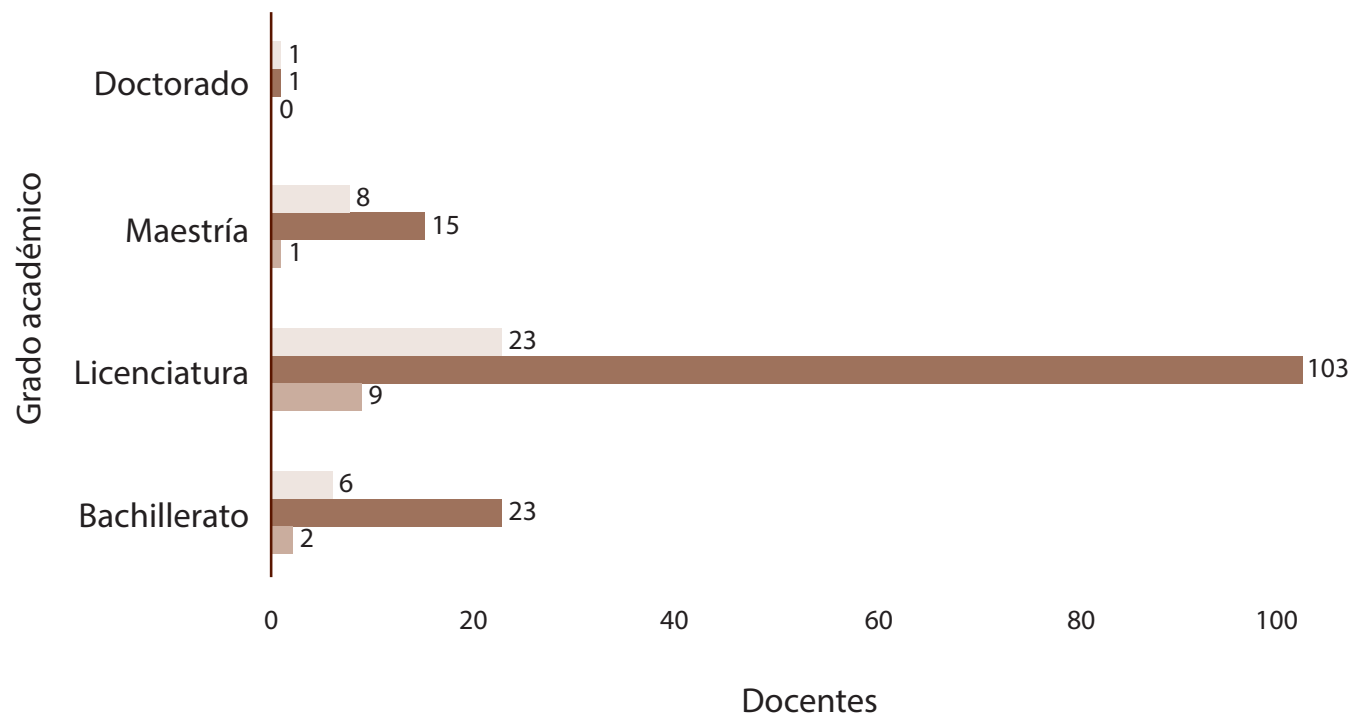

Secundaria Primaria Preescolar

Figura 2: Grado académico y nivel donde labora el colectivo docente.

La edad del colectivo docente que ha participado en el estudio oscila entre los 27 y los 65 años ( $M d=38 ; \bar{X}=43.2 ; \sigma=8.6)$. Del grupo participante, 154 son mujeres $(80.2 \%)$, mientras 38 docentes son hombres (19.8\%). En cuanto a la distribución por grado académico que poseen, 31 (16.1\%) tienen Bachillerato, 134 (69.8\%) Licenciatura y, los restantes 25 (13\%) poseen una Maestría y solamente 2 personas (1.0\%) indican tener un Doctorado. En la Figura 2 se pueden observar los datos comparados por grado académico y nivel.

En cuanto a las áreas de formación del colectivo docente (Figura 3), se observa cómo la mayoría, 132 (69\%) pertenecen a educación; 18 (10\%) a ciencias naturales; 16 personas (8\%) a ciencias sociales; 14 (7\%) al área de idiomas y finalmente $12(6 \%)$ personas se ubican en diferentes áreas distintas a las mencionadas. 


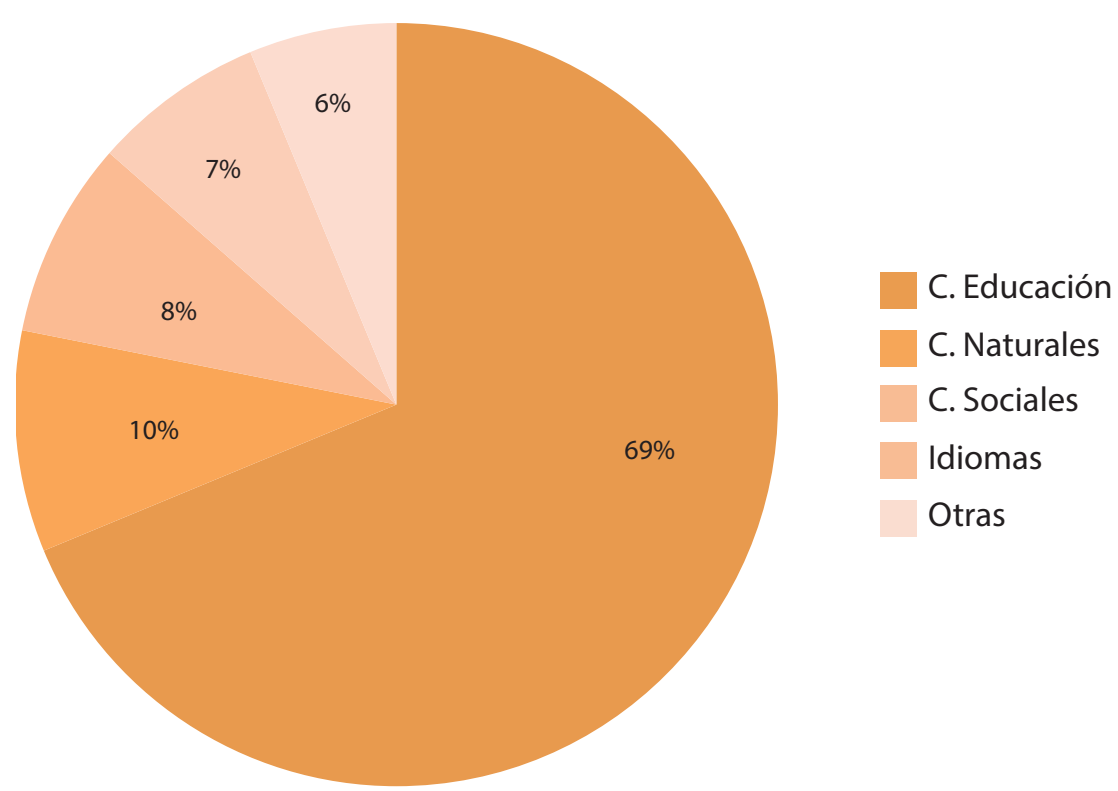

Figura 3: Distribución del colectivo docente según área de formación.

Igualmente, se entrevistó a seis personas encargadas de la dirección que laboran en centros educativos públicos, concretamente uno de preescolar; tres de primaria y dos de secundaria. Las edades quedan comprendidas en un rango que oscila entre 41 y 55 años. En todos los casos, tienen experiencia en dirección superior a los 8 años y como mínimo 3 años de laborar en la institución en el momento de la entrevista.

\section{Técnicas de recolección de datos}

Teniendo en cuenta aspectos tanto teóricos como metodológicos, se abordó un estudio por encuesta (Torrado, 2014), con la utilización de dos instrumentos de recolección de datos.

En primer lugar, se utilizó un cuestionario elaborado ad hoc, para conocer la percepción docente, que quedó compuesto por cuatro bloques, con un total de 89 ítems. El primero responde a aspecto generales (12 ítems) con preguntas cerradas; el segundo basado en aspectos relacionados con la gestión curricular (19ítems), un tercero que, aunque vinculadoal anterior, se opta por separarlo, y corresponde a procesos pedagógicos y de aula (30 ítems); por último, un bloque de aspectos relacionados con la gestión administrativa (24 ítems). Para el presente artículo nos centraremos en los resultados del bloque de gestión curricular, y procesos pedagógicos y de aula.

Los bloques en cuestión quedan compuestos por dos escalas tipo Likert, ambas con cinco opciones de respuesta desde muy de acuerdo (5) hasta muy en desacuerdo (1) la primera de ellas y una segunda desde nunca (1) hasta siempre (5). 
La estructura del cuestionario es el resultado de un proceso de validación de contenido a través de juicio de personal experto (Cohen y Manion, 1990; McMillan y Schumacher, 2005). Para la elaboración se realizó una lluvia de ideas entre los componentes del grupo investigador a cargo del proyecto, de donde se obtuvo un primer borrador, el cual fue sometido a juicio del grupo experto para la validación de contenido que "se refiere al grado en que un instrumento refleja el dominio específico de contenido de lo que se mide" (Hernández et al., 2010, p. 2010), concretamente se envió el cuestionario a cuatro personas expertas tanto en el área de administración educativa como en investigación.

Los ítems, una vez validados, se incluyen en el cuestionario y se someten a pruebas de correlación de Pearson entre cada uno de los componentes y la escala total, y como se observa en la Tabla 2 correlacionan en cada uno de los casos.

Tabla 2: Matriz de correlaciones puntuación total y dimensiones

\begin{tabular}{lcccc}
\hline & $\begin{array}{c}\text { Escala } \\
\text { total }\end{array}$ & $\begin{array}{c}\text { Gestión } \\
\text { curricular }\end{array}$ & $\begin{array}{c}\text { Procesos pedagógicos } \\
\text { y áulicos }\end{array}$ & $\begin{array}{c}\text { Gestión } \\
\text { administrativa }\end{array}$ \\
\hline Escala total & 1 &, $520^{* *}$ &, $601^{* *}$ &, $568^{* *}$ \\
Gestión curricular & & 1 &, $421^{* *}$ &, $459^{* *}$ \\
Procesos pedagógicos y áulicos & & 1 &, $286^{* *}$ \\
\hline
\end{tabular}

** La correlación es significativa al nivel 0,01 (bilateral).

Se realizaron las pruebas para el cálculo de consistencia interna Alpha de Cronbach y se obtuvieron los datos que se muestran en la Tabla 3, tanto para la escala total como para cada una de las dimensiones. Como se observa en todos los casos es superior a 0.7 , considerado por la teoría como fiable.

Tabla 3: Coeficiente de consistencia interna para la escala total y las dimensiones

\begin{tabular}{lc}
\hline \multicolumn{1}{c}{ Escala } & Alfa de Cronbach \\
\hline Escala total & 0.800 \\
Dimensión gestión curricular & 0.862 \\
Dimensión procesos pedagógicos y áulicos & 0.853 \\
Dimensión administrativa & 0.756 \\
\hline
\end{tabular}

Por otro lado, se utilizó la entrevista para recolectar información de la dirección de centros. Desde una perspectiva de estructura, la entrevista utilizada es semiestructurada, ya que se realizó un protocolo con un guion que orienta sobre la información necesaria por recoger, pero a través de preguntas abiertas para obtener diferentes matices en la información obtenida (Torrado, 2014). 
doi: http://dx.doi.org/10.15359/ree.22-1.11

URL: http://www.una.ac.cr/educare

CORREO: educare@una.cr

\section{Presentación de resultados}

Para una mejor comprensión, la presentación de resultados obtenidos del colectivo docente se realiza a través de gráficos y tablas estadísticas; y la percepción de la dirección de centros educativos se presenta en formato tabular, respondiendo a cada uno de los objetivos planteados desde ambas perspectivas metodológicas.

\section{Aspectos de mayor relevancia que intervienen en la gestión curricular}

Como se puede apreciar en la Figura 4, algunos de los aspectos que el colectivo docente considera pertinentes a la gestión curricular, donde indican estar muy de acuerdo o de acuerdo, son la mediación pedagógica y los programas de los cursos (83\%), aspectos como la evaluación docente, laboratorios o materiales (75\% aproximadamente). Por el contrario, aspectos como el transporte, el Patronato Escolar o la Junta de Educación casi la mitad de la muestra indica no saberlo, estar en desacuerdo o muy en desacuerdo.

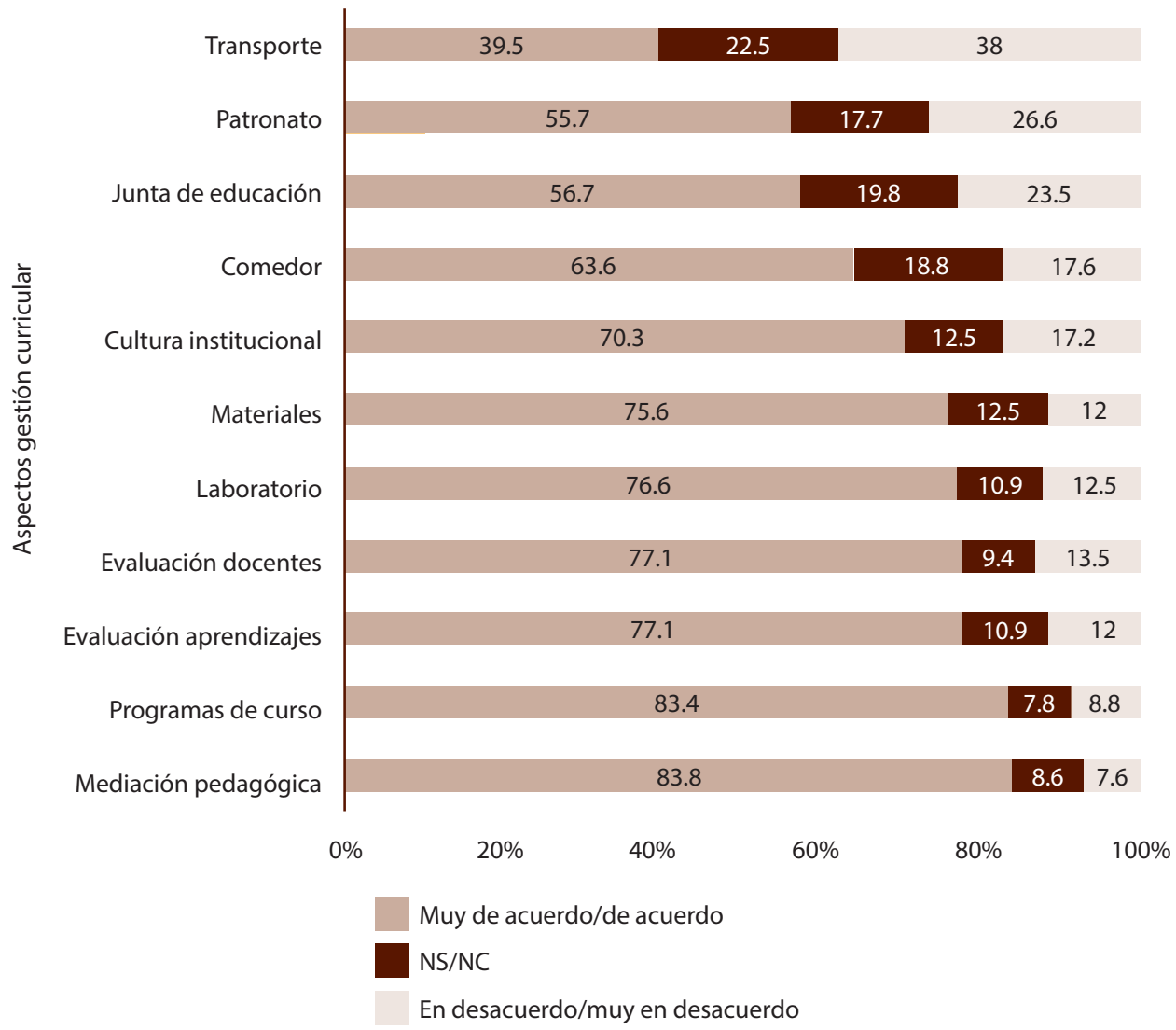

Figura 4: Percepción docente sobre los principales aspectos que contempla la gestión curricular. 
En la Tabla 4, pueden observarse tres de las definiciones que realizan sobre la composición de la gestión curricular, las personas informantes pertenecientes a la dirección de los centros. Se detecta, en algunos casos, como se tiene una posición integral sobre la gestión curricular; por el contrario, hay un informante que lo asocia exclusivamente con el quehacer académico.

Tabla 4: Percepción sobre la composición de la gestión curricular

\begin{tabular}{cl} 
Informante & ¿Qué comprende por gestión curricular? \\
\hline $1 \quad$ "Contempla acciones, organización de la atención del servicio educativo que el estudiante requiere, \\
educación integral, necesidades educativas, nutricionales, culturales, etc., y como institución \\
debemos estables procesos que permitan brindar al estudiantado todas esa esas necesidades de \\
manera satisfactoria". \\
"Aquellas acciones que tienen que ver propiamente con el quehacer académico en las aulas, \\
procesos que se dan en las aulas especialmente". \\
"Lo curricular es diferente de lo administrativo, el docente desarrolla su trabajo y planeamiento
\end{tabular}

\section{Conocimiento respecto a la procedencia de las políticas curriculares que se implementan en los centros educativos}

En cuanto a la procedencia de las políticas curriculares, la gran mayoría del colectivo encuestado (82,8\%) considera que vienen del Ministerio de Educación Pública (MEP), resalta el restante $(17,2 \%)$ que no sabe o está en desacuerdo con la procedencia de las políticas por parte del Ministerio. Cabe destacar que aproximadamente el $50 \%$ de la muestra indica estar en desacuerdo o muy en desacuerdo con la procedencia de las políticas por parte de organismos tanto nacionales (universidades públicas), como internacionales (UNESCO, Banco Mundial, etc.) y donde solamente el $25 \%$ esta de acuerdo con la emanación de políticas desde estos entes.

En cuanto a la procedencia de las políticas curriculares, en la Tabla 5 pueden visualizarse las repuestas del personal responsable de la dirección de los centros educativos. En estas mismas se observa cómo consideran que responden tanto a nivel nacional, internacional como a ambos simultáneamente. 
doi: http://dx.doi.org/10.15359/ree.22-1.11

URL: http://www.una.ac.cr/educare

CORREO: educare@una.cr

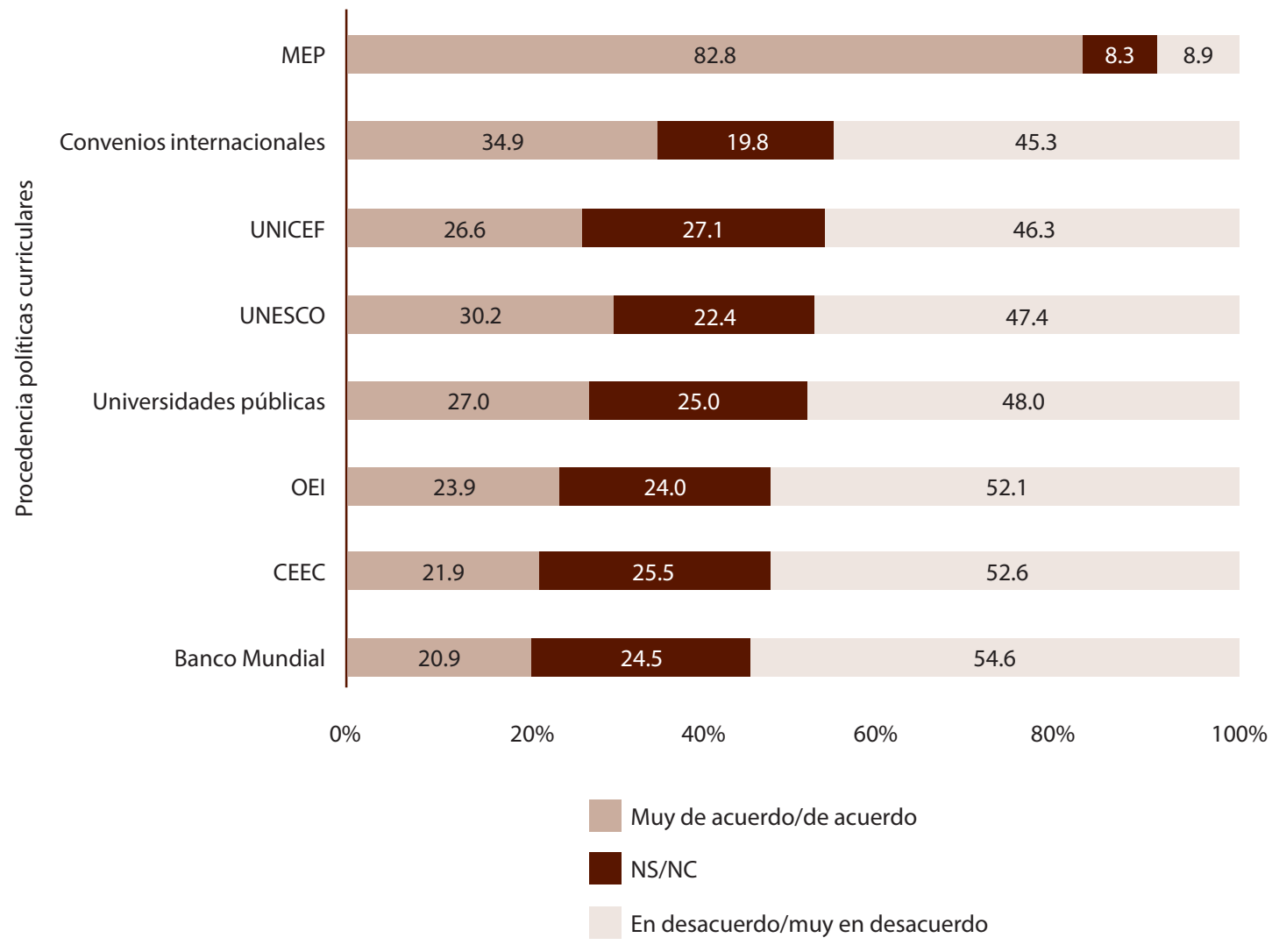

Figura 5. Percepción docente sobre la procedencia de las políticas curriculares.

Tabla 5: Percepción de la dirección sobre la procedencia de las políticas curriculares

Informante ¿Las pautas en materia de gestión curricular responden a un diseño de políticas nacionales o internacionales?

2 "Responden a políticas internacionales, tendemos a copiar lo de otros países, por ejemplo, a Chile, aunque ahora estemos diez años atrás".

4 "A políticas nacionales, ya que se ajustan a la realidad nacional. Las autoridades han tomado conciencia de que no podemos seguir así".

6 "Tanto nacionales como internacionales, ya que el país no funciona fuera del contexto de América Latina".

José Antonio García-Martínez, Virginia Cerdas-Montano y Nancy Torres-Vitoria
Los artículos de la Revista Electrónica Educare del Centro de Investigación y Docencia en Educación de la Universidad Nacional, Costa Rica, se comparten bajo términos de la Licencia
Creative Commons: Reconocimiento, No Comercial, Sin Obra Derivada 3.0 Costa Rica. Las autorizaciones adicionales a las aquí delimitadas se pueden obtener en el correo: educare@una.cr




\section{Principales redes de apoyo con que cuentan los centros educativos}

En la Tabla 6, se presentan las frecuencias absolutas obtenidas dentro de una escala donde 1 corresponde a "nunca"; 2 "casi nunca"; 3 "algunas veces"; 4 "casi siempre" y 5 "siempre", además de la media y desviación típica. Como puede observarse, los ítems mejor valorados corresponden al acompañamiento que perciben para las adecuaciones curriculares por parte del Comité de Adecuaciones Curriculares ( $\bar{X}=3.3 ; \sigma=1.4)$; seguido de la información sobre los programas del MEP para apoyo a estudiantes y los mecanismos del Centro para divulgar los nuevos proyectos del MEP ( $\bar{X}=3.2 ; \sigma=1.4)$. En cuanto a los ítems menos valorados destaca el apoyo recibido por padres y madres de familia $(\bar{X}=2,3 ; \sigma=1.4)$, así como del Patronato Escolar y la Junta de Educación $(\bar{X}=2,7 ; \sigma=1.4)$ en todos los casos referidos a materiales didácticos. En

Tabla 6: Frecuencias de la percepción docente sobre aspectos pedagógicos

\begin{tabular}{|c|c|c|c|c|c|c|c|}
\hline & 1 & 2 & 3 & 4 & 5 & $\bar{x}$ & $\sigma$ \\
\hline En su centro educativo se realizan proyectos de apoyo a la mediación pedagógica & 25 & 34 & 61 & 40 & 30 & 3.1 & 1.2 \\
\hline Recibo apoyo de la Dirección de centro para el material didáctico & 41 & 31 & 46 & 39 & 34 & 3.0 & 1.4 \\
\hline Recibo apoyo del Patronato Escolar para el material didáctico & 77 & 40 & 34 & 14 & 26 & 2.3 & 1.4 \\
\hline Recibo apoyo de padres y madres de familia para el material didáctico & 47 & 36 & 59 & 32 & 17 & 2.7 & 1.3 \\
\hline $\begin{array}{l}\text { Recibo apoyo de la Junta de Educación/ Junta administrativa para el material } \\
\text { didáctico }\end{array}$ & 52 & 29 & 52 & 25 & 33 & 2.8 & 1.4 \\
\hline $\begin{array}{l}\text { Estoy informado/a de la existencia de programas del MEP para apoyo a } \\
\text { estudiantes }\end{array}$ & 32 & 31 & 41 & 46 & 41 & 3.2 & 1.4 \\
\hline $\begin{array}{l}\text { La Dirección del centro tiene mecanismos eficientes para divulgar los nuevos } \\
\text { proyectos del MEP }\end{array}$ & 24 & 32 & 51 & 46 & 38 & 3.2 & 1.3 \\
\hline $\begin{array}{l}\text { Recibo acompañamiento para las adecuaciones curriculares por parte de la } \\
\text { Dirección }\end{array}$ & 45 & 36 & 44 & 32 & 34 & 2.9 & 1.4 \\
\hline $\begin{array}{l}\text { Recibo acompañamiento para las adecuaciones curriculares por parte de } \\
\text { equipo interdisciplinario }\end{array}$ & 42 & 32 & 49 & 35 & 32 & 2.9 & 1.4 \\
\hline $\begin{array}{l}\text { Recibo acompañamiento para las adecuaciones curriculares por parte del } \\
\text { Comité de Adecuaciones Curriculares. }\end{array}$ & 30 & 25 & 46 & 41 & 48 & 3.3 & 1.4 \\
\hline
\end{tabular}

cuanto a las respuestas por parte de la dirección (Tabla 7) respecto al apoyo del centro para la mediación pedagógica, se observa que se centran, en gran medida, en relación con el material didáctico disponible para el desarrollo de las clases. 
doi: http://dx.doi.org/10.15359/ree.22-1.11

URL: http://www.una.ac.cr/educare

CORREO: educare@una.cr

Tabla 7: Percepción de la dirección sobre el apoyo a la mediación pedagógica

\begin{tabular}{|c|c|}
\hline Informante & ¿Qué acciones se desarrollan en el centro educativo que apoyan la mediación pedagógica? \\
\hline 2 & $\begin{array}{l}\text { "Todo lo que se hace en el centro es para favorecer al estudiantado, construyendo cultura donde } \\
\text { la importancia recae en este: infraestructura, becas, odontología, comedor, etc., pero para ello es } \\
\text { básico la auto capacitación docente". }\end{array}$ \\
\hline 4 & $\begin{array}{l}\text { "Se trabajan encerronas con los compañeros, de la mano con el comité de capacitación, se contacta } \\
\text { a la regional para capacitaciones, se recurre al comité de apoyo para adecuaciones curriculares, etc." }\end{array}$ \\
\hline 6 & $\begin{array}{l}\text { "Si necesitan material la Junta de Educación se lo facilita, según lo requieran, además el docente } \\
\text { recibe un incentivo didáctico para cubrir la compra de materiales". }\end{array}$ \\
\hline
\end{tabular}

\section{Aspectos más relevantes que se vinculan con la promoción estudiantil y fracaso escolar}

Al consultar al colectivo docente sobre aspectos relacionados con la promoción estudiantil (figura 6) se observa cómo da mayor valor al esfuerzo docente y mediación docente, donde han contestado (82,5\%) que está relacionado siempre o casi siempre; en menor medida lo relacionan con el esfuerzo estudiantil $(61,5 \%)$ y aproximadamente el $50 \%$ del colectivo lo relaciona con el apoyo de la familia, la gestión del centro y los programas de estudios. Cabe resaltar que aspectos como el acceso a tecnologías y políticas educativas no son vinculados a la promoción estudiantil, donde aproximadamente el $25 \%$ indica nunca o casi nunca.

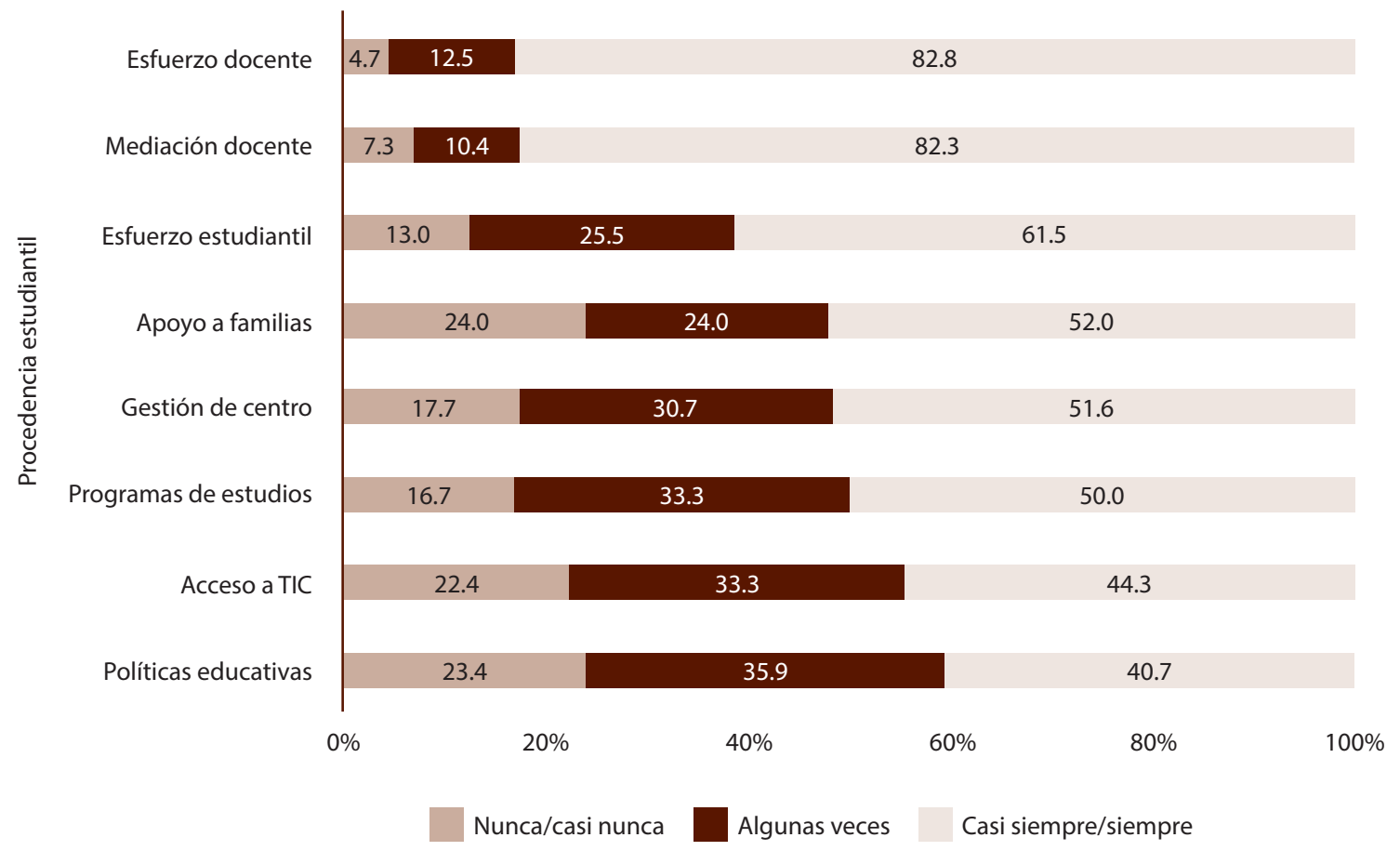

Figura 6: Percepción docente sobre los principales aspectos de la promoción estudiantil 
En cuanto al fracaso escolar, como se puede ver en la Figura 7, indican que se vincula siempre o casi siempre con aspectos como la falta de apoyo familiar $(68,3 \%)$; falta de interés del estudiantado $(65,6 \%)$ o ausentismo (59,9\%). Otros aspectos como la mediación docente, programas de curso y la gestión del centro quedan distribuidos homogéneamente en las diferentes categorías de respuesta, destaca que aproximadamente el $30 \%$ indica que nunca o casi nunca, un $40 \%$ indica que algunas veces y otro $30 \%$ dice que siempre o casi siempre. Por último, destaca cómo el colectivo docente no vincula en gran medida las directrices educativas y la pobreza $(41,7 \%$ y $28,7 \%)$, indicando nunca o casi nunca.

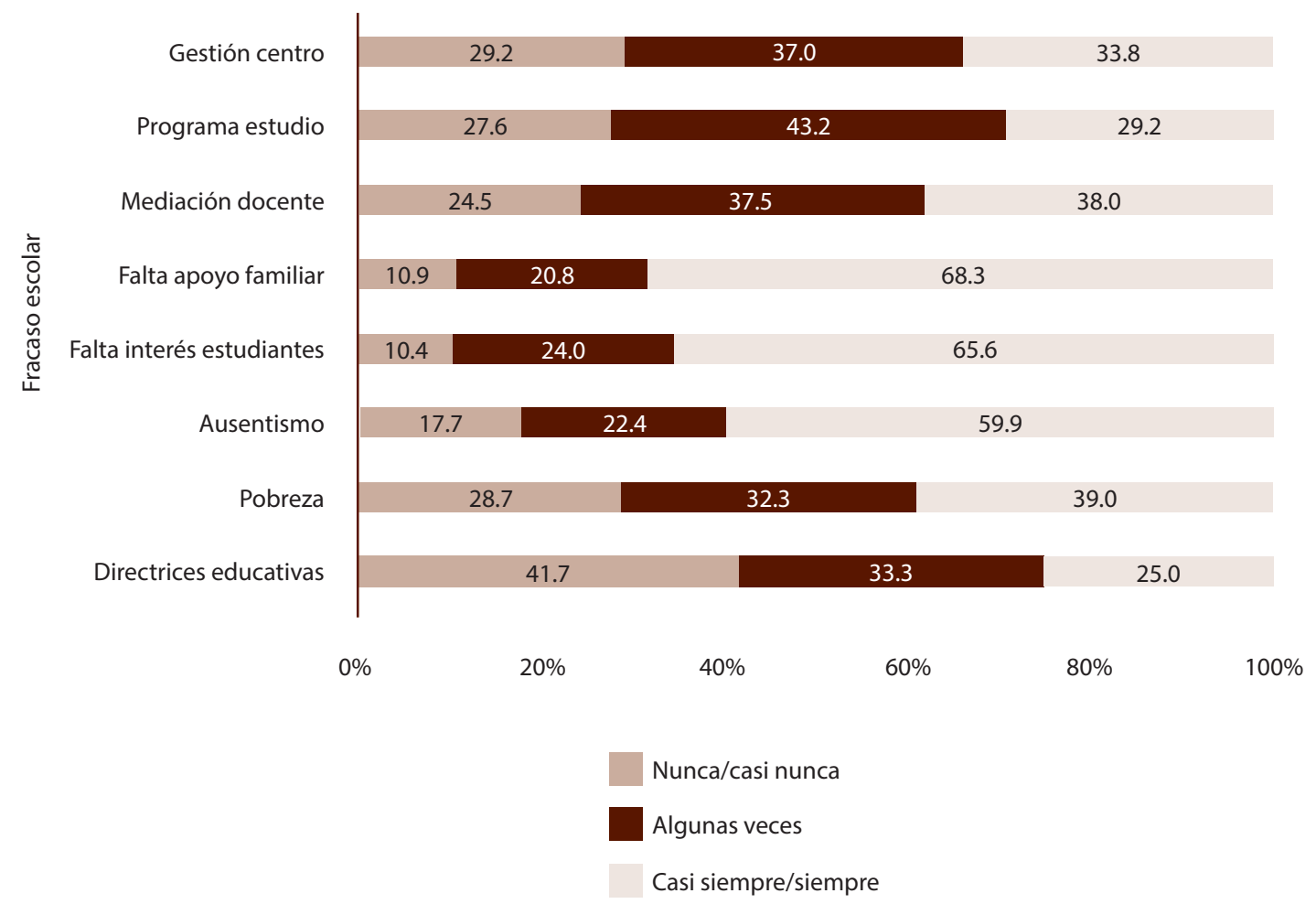

Figura 7: Percepción docente sobre los principales aspectos relacionados al fracaso escolar.

Por su parte, los sujetos informantes responsables de la dirección (Tabla 8) expresan que ese indicador, como puede observarse, varía considerablemente de un centro a otro. En cuanto a los motivos, igualmente son diversos, ya que los relacionan con compromiso y el apoyo familiar en los casos donde el indicador es elevado (98\%), mientras que se asocia al ausentismo y la falta de apoyo familiar en el caso donde el indicador es mucho más bajo (45\%). Igualmente, existen diferencias en cuanto a la percepción que se tiene sobre dicho indicador. 
doi: http://dx.doi.org/10.15359/ree.22-1.11

URL: http://www.una.ac.cr/educare

CORREO: educare@una.cr

Tabla 8: Percepción de la dirección sobre aspectos de promoción y fracaso escolar

\begin{tabular}{|c|c|c|c|}
\hline \multirow[b]{2}{*}{ Informante } & \multirow[b]{2}{*}{ Indicador } & \multicolumn{2}{|c|}{ Resultados y percepción sobre el indicador de promoción estudiantil } \\
\hline & & Motivos & Percepción sobre el indicador \\
\hline 2 & $100 \%$ & $\begin{array}{l}\text { "no se puede retener a un niño, y } \\
\text { solamente con casos calificados y a través } \\
\text { del MEP". }\end{array}$ & $\begin{array}{l}\text { "Quien toma las decisiones no están en las } \\
\text { aulas, hay niños y niñas que requieren más } \\
\text { tiempo en preescolar". }\end{array}$ \\
\hline 4 & $98 \%$ & $\begin{array}{l}\text { "por un personal muy comprometido, } \\
\text { apoyo de familias, comité de apoyo". }\end{array}$ & $\begin{array}{l}\text { "No indica calidad, ya que falta mucho por } \\
\text { hacer, por ejemplo, en cuanto a reciclaje, } \\
\text { aunque los indicadores sean altos". }\end{array}$ \\
\hline 6 & $45 \%$ & $\begin{array}{l}\text { "por el ausentismo, muchos estudiantes } \\
\text { solo vienen al comedor, los papás son muy } \\
\text { irresponsables y le cargan todo al sistema". }\end{array}$ & $\begin{array}{l}\text { "Considero que el indicador es muy } \\
\text { relevante". }\end{array}$ \\
\hline
\end{tabular}

\section{Discusión y conclusiones}

Las percepciones del personal docente y directivo sobre aspectos relevantes de la gestión curricular son necesarias para comprender las prácticas cotidianas en los centros educativos. Si se requieren cambios para los procesos de mejoramiento en los centros educativos, hay que centrar la atención en lo que piensan sus miembros. De aquí que esta investigación aporta algunos elementos de análisis que pueden dinamizar diálogos académicos alrededor de la gestión curricular.

Sin embargo, antes de adentrarse al análisis de los resultados, es importante reconocer que un alto porcentaje de docentes en ejercicio posee un grado de Licenciatura, lo que permite aclarar que cuentan con una titulación idónea para ejercer sus labores como profesionales de la educación. Esta condición no garantiza procesos de calidad en los centros educativos, pero se puede asumir que tienen los saberes conceptuales y procedimentales básicos para el ejercicio de sus funciones. Se considera que la titulación como factor endógeno del centro educativo en relación con gestión curricular es un aspecto que puede influir positivamente para el desarrollo de las acciones propias de los procesos educativos, en lo cual se coincide con lo aportado por la UNESCO (2011).

Se puede identificar que los aspectos de mayor relevancia que intervienen en la gestión curricular, desde la percepción de personal docente y directivo, se adjudica a la mediación pedagógica y a los programas de estudio. Esto tiene estrecha relación con las acciones que desarrollan los colectivos docentes desde sus espacios áulicos como lo refieren Inciarte et al. (2006). Esta percepción es compartida por la dirección, ya que los sujetos entrevistados hacen referencia de manera reiterativa a que la gestión curricular son todas aquellas acciones que tienen relación directa con los procesos áulicos (Segura, 2012); hacen hincapié en los procesos de planificación para la ejecución de los contenidos programáticos. 
Si la labor áulica es el espacio inmediato de docentes en donde se vinculan a la gestión curricular, la participación de esta población en procesos de actualización sobre los aspectos curriculares y desarrollo de nuevas habilidades demandantes de la realidad actual tendría que ser un punto medular para los centros educativos, de acuerdo con lo manifestado por DíazBarriga e Inclán-Espinosa (2001).

Desde la gestión curricular se hace relevante la construcción de saberes teóricos y prácticos de sus agentes intervinientes, ya que las prácticas que se accionen en la organización escolar van a depender directamente de estos constructos. La participación colegiada de docentes en esta construcción de saberes cobra relevancia para una gestión curricular que responda a los contextos de cada centro educativo.

Aspectos como el transporte, comedor escolar, el Patronato Escolar o la Junta de Educación, no son visualizados por los grupos docentes como parte relevante de la gestión curricular. Esta percepción se puede relacionar con lo que apunta Castro (2005), quien establece los procesos áulicos como aquellos de mayor relevancia para docentes en asociación con el currículo, dado que es, en este espacio, donde tienen mayor autonomía de acción y, además, el colectivo docente lo considera como una de las actividades centrales de su quehacer y del centro educativo.

En esta misma línea de análisis, se podría decir que servicios como el transporte, el comedor escolar entre otros aspectos, son asumidos por el cuerpo docente como factores exógenos de la gestión curricular. Para este cuerpo, no está categorizado como parte de sus responsabilidades y, por tanto, se pone en la periferia de la gestión curricular.

A pesar de que para los colectivos docentes servicios complementarios u organismos de apoyo como el Patronato Escolar o la Junta de Educación son percibidos como ajenos a la gestión curricular, estos son parte fundamental de la gestión del centro educativo y son, en realidad, un factor endógeno, tal como lo refiere la UNESCO (2011), son parte de las acciones que se deberían gestionar desde la dirección del centro educativo, desde donde se concretizan espacios para la colaboración de docentes, con el fin de brindar mejores condiciones y atención integral al estudiantado.

Desde la percepción docente estos aspectos no se consideran de mayor relevancia en la gestión curricular; no obstante, desde la dirección estos aspectos deberían tener mayor notoriedad, por la naturaleza de las funciones que ejerce la dirección; sin embargo, se encuentra un vacío conceptual también desde la dirección, ya que solamente dos de las personas informantes hacen referencia, como parte de la gestión curricular, a los servicios complementarios de transporte, nutrición y otros aspectos culturales y de tratamiento integral para el estudiantado. Este hallazgo podría disociar la dimensión pedagógica de su integralidad o segmentar los elementos que la conforman y repercutir en las prácticas que se desarrollan en los centros educativos. 
doi: http://dx.doi.org/10.15359/ree.22-1.11

URL: http://www.una.ac.cr/educare

CORREO: educare@una.cr

Programas de apoyo como el de transporte, comedor escolar, además de organizaciones como el Patronato y la Junta de Educación se consideran responsabilidad de la dirección de los centros educativos. De los hallazgos se deriva una clara distancia en la división de tareas y roles para la administración de los recursos institucionales como lo refieren Chen y Vargas (2007), donde ni los grupos docentes, ni la dirección asumen estos aspectos como parte de la gestión curricular, lo que devela una mirada de la dimensión curricular centrada únicamente en los procesos de enseñanza-aprendizaje, y que puede incidir en la percepción docente sobre los indicadores de logro, que se discuten más adelante.

El hecho educativo se caracteriza por generar dinámicas complejas, cambiantes, entre otras, por lo que se abordan algunos elementos como las políticas curriculares que interesan analizar para fines de esta investigación desde una mirada multidimensional. En este sentido, la emanación de políticas curriculares desde la percepción docente es adjudicada casi que exclusivamente al Ministerio de Educación Pública y manifiesta desconocimiento de la enorme importancia que tienen otros organismos en el diseño, ejecución y evaluación de estas mismas, como plantea Brenes (2015). En contraposición con esta percepción, las personas informantes de la dirección, en su totalidad, tienen meridiana claridad sobre el origen tanto de carácter nacional como internacional, estableciendo un grado de relevancia para la gestión curricular que concuerda con lo referido por la CECC/SICA (2013).

De acuerdo con los expuesto por Soler y Martínez (2014), se puede concluir que la participación docente es necesaria para el desarrollo de políticas curriculares y que esta misma participación se vuelve sustantiva en la gestión curricular, ya que permite repensar sobre su propio quehacer y poder identificar sus aciertos y desaciertos en su trabajo cotidiano, favoreciendo el mejoramiento de los procesos de calidad. Cuando se abren espacios de diálogo académico se incrementan posibilidades de una comprensión multidimensional del quehacer educativo. La participación docente en espacios de diálogo académico permitiría mayor comprensión de la dimensión integral de la educación y no desde una visión fragmentada.

La educación como proceso intencionado en la formación de una ciudadanía requiere que las personas que concretizan los planes y programas tengan un panorama amplio hacia donde se dirigen las acciones y, desde esta comprensión, generar significado, significantes y transformaciones para asumir su responsabilidad en el rol que tienen como profesionales de la educación en el proceso formativo.

Para que las políticas educativas tengan impacto en las diversas poblaciones inmersas en los procesos educativos, se hace necesaria una participación más activa del colectivo docente y de la dirección. En la lectura de los contextos educativos se requiere de la participación de las personas que están inmersas en estos y que pueden aportar elementos sustantivos para la búsqueda de soluciones, que respondan a las realidades diversas. La gestión curricular concebida como una 
construcción multidimensional y multifactorial precisa de cuestionamientos, análisis y reflexiones sobre las políticas y sus posibles implicaciones en la vida de las personas y las comunidades.

En relación con la percepción de las redes de apoyo con que cuentan los centros educativos, los grupos docentes valoran, en mayor medida, al Comité de Adecuaciones Curriculares, que tiene a su cargo el acompañamiento de docentes para cumplir con los procesos requeridos por el MEP en dicha materia. Se denota, en contraposición, el apoyo de organismos como el Patronato Escolar y la Junta de Educación en relación con materiales de apoyo áulico, ya que esta dotación de materiales didácticos se adjudica a la dirección. Bernasconi (2009) refiere este vínculo de interdependencia con la dirección como red de apoyo para suministro de materiales didácticos, ya que es precisamente la dirección escolar con la que establecen sus vínculos relacionales con mayor frecuencia y permanencia.

En alguna medida, las adecuaciones también tienen relevancia para la dirección, pues refieren al Comité de Adecuaciones Curriculares como parte de las redes de apoyo para la capacitación de docentes. Sin embargo, la percepción de la dirección hacia redes de apoyo para la mediación pedagógica es más amplia, ya que algunos informantes de la dirección se refieren a una atención integral del estudiantado y aportan elementos como la cultura institucional, servicios de becas, odontología, comedor escolar, sin dejar de mencionar los organismos de apoyo que se accionan desde el centro educativo. Esto, como parte de las redes de apoyo para la mediación pedagógica. Cabe destacar que, según los resultados, ninguno de los colectivos de actores objeto de estudio evidencia conocimientos sobre la importancia de los espacios de participación que los organismos de apoyo brindan a la experiencia de vida de personas sin formación profesional que interactúan de manera directa con los procesos de educación.

Una vez más, los espacios de diálogo académico toman un sitio privilegiado, para todo aquel centro educativo que desee establecer una gestión curricular pertinente a su contexto. Es preocupante que los cuerpos docentes refieran en un alto porcentaje, que nunca o casi nunca se realicen proyectos para apoyar la mediación pedagógica, lo que coincide con Ortiz (2013) en cuanto a que los procesos pedagógicos son el eje central de la dimensión curricular para el personal docente; se comparte criterio con lo que aporta la UNESCO (2011) en este mismo sentido, al determinar lo pedagógico como la acción sustantiva de la gestión curricular.

En cuanto a los indicadores de logro, la promoción estudiantil, según la percepción docente, se vincula a aspectos relacionados con el esfuerzo docente y la mediación pedagógica. Esta dimensión pone de manifiesto una valoración del personal docente hacia su propio esfuerzo y hacia su mediación como factores relevantes para la promoción estudiantil. Al esfuerzo estudiantil y al apoyo familiar no se le adjudica mayor relevancia para tener una buena promoción. Desde esta percepción, la labor del docente está vinculada directamente con un indicador de logro establecido por el MEP para todos los centros educativos, y se deja en un segundo plano el acceso a las tecnologías y políticas educativas. 
doi: http://dx.doi.org/10.15359/ree.22-1.11

URL: http://www.una.ac.cr/educare

CORREO: educare@una.cr

Por otro lado, el fracaso escolar, desde la percepción docente, se relaciona con la falta de apoyo familiar $y$, en segundo plano, con la falta de interés del estudiantado, que va de la mano con el ausentismo. Deja aspectos como la pobreza y las directrices educativas emanadas por el MEP en último término de relevancia.

Se puede observar una contradicción sustantiva en estos dos indicadores consultados desde la perspectiva docente: en primera instancia, la promoción estudiantil se vincula con la labor docente, dejando el esfuerzo estudiantil como un aspecto de menor relevancia; sin embargo, cuando se analiza el indicador de fracaso escolar la responsabilidad recae en la falta de apoyo familiar y en la falta de interés del estudiantado. Como se puede comprender, esta contradicción refiere el éxito a los cuerpos docentes y el fracaso a los padres, madres de familia y al estudiantado.

Esta situación se ve reflejada también en la percepción de la dirección, ya que algunas de las personas entrevistadas manifiestan que la promoción estudiantil está ligada al compromiso de docentes y al apoyo familiar. También denotan que algunos padres y madres de familia envían a sus hijos al centro educativo para recibir el servicio de comedor escolar; la pobreza surge como un aspecto asociado con la "irresponsabilidad de las familias". Este último queda sin relevancia para los grupos docentes, quienes no consideran la pobreza como un aspecto relacionado con la promoción estudiantil. Esta percepción es coherente con lo que Gómez-Sevilla y SánchezMendoza (2013) aportan a la discusión, cuando mencionan que los indicadores son asumidos por los centros educativos desde la verificación y la evaluación. En este caso, se considera que estos indicadores, además de tener una connotación de evaluación y verificación, tanto dirección como docentes la vinculan directamente al desempeño de sus funciones, de donde se extraen contradicciones como las que se establecen en este análisis.

Por otro lado, la UNESCO (2011) hace referencia a factores endógenos y exógenos de la gestión curricular, entre los que se pueden encontrar el desempeño docente, que es ubicado como un factor endógeno y se adjudica la responsabilidad directa al centro educativo de su gestión. Asimismo, el apoyo de las familias se ubica, según la UNESCO (2011), como factor exógeno, el cual es asumido por docentes y parte de las personas informantes de la dirección, como un aspecto en el cual no tienen una injerencia directa y al cual le otorgan la responsabilidad del fracaso escolar.

\section{Recomendaciones}

En relación con los resultados obtenidos en la investigación, se recomienda a las instituciones de educación superior, contemplar en su programa de estudios una concepción de gestión curricular integral, que evite la fragmentación, para superar una visión centrada en los procesos áulicos y programas de estudios. 
Desde los centros educativos es necesario abrir espacios de diálogo que permitan abordar el tema de políticas curriculares y su relación con las prácticas cotidianas, para favorecer una relación directa entre las políticas y la responsabilidad de educadores y educadoras, que contribuya, de esta manera, con una comprensión multidimensional del quehacer educativo y propicie una participación activa y crítica en la gestión de las políticas curriculares.

En relación con los equipos de apoyo, se recomienda a la gestión de los centros educativos abrir espacios de diálogo con la comunidad educativa, para que permitan comprender el papel de las redes de apoyo y cómo operan en cada centro educativo, ya que la legitimación de estas mismas es relevante para articular esfuerzos y alcanzar metas comunes.

Finalmente, tanto la promoción como el fracaso escolar son dos indicadores que se vinculan a un esfuerzo colaborativo de la comunidad educativa, por tanto, cobra sentido hacer esfuerzos en los espacios de formación docente y los centros educativos para comprender que la educación es un proceso de construcción social y no se puede adjudicar de forma individual la responsabilidad de los resultados, ya sean de éxito o de fracaso.

\section{Referencias}

Bernasconi, G. (2009). Red AGE: La red de apoyo a la gestión educativa en Ibero-América. En X Encuentro Internacional Virtual Educa (pp. 1-18). Buenos Aires: UCA. Recuperado de http:// www.redage.org/sites/default/files/adjuntos/RedAGE\%20 red gesti\%C3\%B3n\%20 educativa\%20en\%20lberoam\%C3\%A9rica.pdf

Brenes, M. (2015). Las innovaciones pedagógicas y la gestión de la educación en la Escuela Nueva Laboratorio“Emma Gamboa" de la Universidad de Costa Rica y el Instituto Educativo Moderno. Revista Gestión de la educación, 5(2), 39-68. doi: https://doi.org/10.15517/rge. $\underline{\mathrm{v} 5 \mathrm{i} 2.19939}$

Castro, F. (2005). Gestión curricular: Una nueva mirada sobre el currículum y la institución educativa. Revista Horizontes Educacionales, 10, 13-25. Recuperado de http://www.redalyc. org/pdf/979/97917573002.pdf

Cerdas-Montano, V., Torres-Vitoria, N. y García-Martínez, J. A. (2016). Tendencias y desafíos de la administración educativa costarricense: La génesis de un proyecto. Revista Gestión de la Educación, 6(2), 119-136). doi: https://doi.org/10.15517/rge.v2i1.8593

Chen. E. y Vargas. I. (2007). Administración de recursos institucionales en centros educativos. Heredia, Costa Rica: EUNA.

Cohen, L. y Manion, L. (1990). Métodos de investigación educativa. Madrid: La Muralla. 
doi: http://dx.doi.org/10.15359/ree.22-1.11

URL: http://www.una.ac.cr/educare

CORREO: educare@una.cr

Coordinación Educativa y Cultural Centroamericana (CECC/SICA). (2013). Política educativa centroamericana 2013-2021. Recuperado de http://ceducar.info/redvc/CEDUCAR/ visor/politica regional/Politica Educativa/HTML/files/assets/common/downloads/ publication.pdf

Creswell, J. W. (2009). Research Design: Qualitative, quantitative, and mixed methods approaches ( $3^{\mathrm{a}}$ ed.). Londres: Sage.

Da Silva, T. T. (2013). Currículo, conhecimento e democracia: As lições e as dúvidas de duas décadas. Cadernos de Pesquisa, 73, 59-66. Recuperado de http://publicacoes.fcc.org.br/ ojs/index.php/cp/article/view/1097

Departamento de Análisis Estadístico, Ministerio de Educación Pública. (2017). Instituciones en educación regular por: Dependencia y zona según: Nivel de enseñanza, rama y horario de trabajo, año 2015. Recuperado de http://www.mep.go.cr/indicadores edu/cifras instituciones4.html

Díaz-Barriga, Á. e Inclán-Espinosa, C. (2001). El docente en las reformas educativas: Sujeto o ejecutor de proyectos ajenos. Revista Iberoamericana de educación, 25, 17-41. Recuperado de http://www.redalyc.org/pdf/800/80002502.pdf

Díaz-Barriga, Á., Luna, A. B. y Jiménez-Vásquez, M. S. (2015). La formación docente para la reforma integral de educación básica en el nivel primaria. La pertinencia pedagógica del diplomado para docentes de primero y sexto grado. Revista Latinoamericana de Estudios Educativos, 45(2), 63-100. Recuperado de http://www.redalyc.org/pdf/270/27039624004.pdf

Gómez-Sevilla, H. N. y Sánchez-Mendoza, V. (2013). Indicadores cualitativos para la medición de la calidad en la educación. Educación yeducadores, 16(1), 9-24. doi: https://doi.org/10.5294/ edu.2013.16.1.1

Hernández, R., Fernández, C. y Baptista, M. (2010). Metodología de la investigación. México D.F.: Editorial McGraw-Hill. Recuperado de https://www.esup.edu.pe/descargas/ dep investigacion/Metodologia\%20de\%20la\%20investigaci\%C3\%B3n\%205ta\%20 Edici\%C3\%B3n.pdf

IIPE-UNESCO. (2004). Gestión administrativa. Recuperado de http://www.mineduc.gob.gt/ digecade/documents/4 gestionadministrativa.pdf

Inciarte, A., Marcano, N. y Reyes, M. (2006). Gestión académico-administrativa en la educación básica. Revista Venezolana de Gerencia, 11(34), 221-243. Recuperado de http://www. produccioncientificaluz.org/index.php/rvg/article/view/10434/10422 
McMillan,J.H.ySchumacher,S.(2005).Investigacióneducativa(5aed.).Madrid:Pearson. Recuperado de $\quad$ http://des.for.infd.edu.ar/sitio/upload/McMillan_J. H. Schumacher S. 2005. Investigacion educativa 5 ed..pdf

Molano, A. D. R. (2016). La gestión educativa: Hacia la optimización de la formación docente en la educación superior en Colombia. Sophia, 12(1), 55-70. doi: https://doi.org/10.18634/ sophiaj.12v.1i.445

Moreira, B. (2016). La práctica docente: Un espacio para el perfeccionamiento de la formación profesional de los estudiantes de la Facultad de Ciencias de la Educación de la Universidad Laica Eloy Alfaro de Manabí. REFCalE: Revista Electrónica Formación y Calidad Educativa, 3(3), 155-166. Recuperado de http://runachayecuador.com/refcale/index.php/refcale/ article/view/1032/612

Ortiz, I. (2013). Gestión curricular en las escuelas con tecnologías de la información y la comunicación sistematización de algunas experiencias en Chile. Perfiles Educativos, 35(141), 152-166. doi: https://doi.org/10.1016/S0185-2698(13)71840-3

Programa Estado de la Nación. (2015). Desigualdades en rendimiento en el sistema educativo costarricense (Capítulo 5). En Programa Estado de la Nación (Ed.), Quinto informe Estado de la Educación (pp. 249-293). San José, Costa Rica: Autor. Recuperado de http://www. estadonacion.or.cr/educacion2015/assets/cap-5-ee-2015.pdf.

Rico, A. D. (2016). La gestión educativa: Hacia la optimización de la formación docente en la educación superior en Colombia. Sophia, 12(1), 55-70. doi: https://doi.org/10.18634/ sophiaj.12v.1i.445

Rodríguez, D. y Valldeoriola, J. (2009). Métodología de la investigación. Barcelona: Universidad Oberta de Catalunya. Recuperado de http://www.zanadoria.com/syllabi/m1019/mat cast-nodef/PID 00148556-0.pdf

Rodríguez-Gómez, D. y Gairín-Sallán, J. (2015). Innovación, aprendizaje organizativo y gestión del conocimiento en las instituciones educativas. Educación, 24(46), 73-90. Recuperado de http://revistas.pucp.edu.pe/index.php/educacion/article/view/12245/12811

Sabariego, M., Massot, I. y Dorio, I. (2014). Capítulo 10. Métodos de investigación cualitativa. En R. Bisquerra (Coord.), (2014). Metodología de la investigación educativa (pp. 293-328). Madrid: Editorial La Muralla.

Segura, M. A. (2012). La autoevaluación: Una reflexión para la gestión de los centros educativos. Revista Gestión de la educación, 2(1), 1-22. doi: https://doi.org/10.15517/rge.v2i1.8593 
Soler, M. L. y Martínez, N. D. (2014). Gestión curricular base de calidad académica. Revista Experiencia Docente, 9-20. Recuperado de http://experienciadocente.ecci.edu.co/index. php/experienciadoc/article/view/29

Tashakkori, A., \&Teddlie, C. (2009). Integrating qualitative and quantitative approaches to research. In L. Bickman, \& D. J. Rog (Eds.), The sage handbook of applied social research methods (2a ed., pp. 283-316). Thousand Oaks, CA: Sage. Doi: https://doi.org/10.4135/9781483348858.n9

Torrado, M. (2014). Capítulo 7. Estudios de encuesta. En R. Bisquerra (Coord.), (2014). Metodología de la investigación educativa (pp. 231-257). Madrid: Editorial La Muralla.

UNESCO. (2011). Manual de gestión para directores de instituciones educativas. Perú: Autor. Recuperado de http://unesdoc.unesco.org/images/0021/002191/219162s.pdf

Vallejo, M. y Molina, J. (2014). La evaluación auténtica de los procesos evaluativos. Revista Iberoamericana de educación, 64, 11-25. Recuperado de http://www.rieoei.org/rie64a01.pdf

Vázquez, M. I. (2013). La autogestión de procesos de cambio en centros educativos. Educación, 22(42), 117-134. Recuperado de http://revistas.pucp.edu.pe/index.php/educacion/article/ view/5294/5291 